\title{
Luiz Antônio Marcuschi e a imortalidade do diálogo
}

\section{Maria Margarida Martins Salomão}

Jorge Luis Borges, numa das belíssimas Conferências que, em 1978, proferiu na Universidade de Belgrano, distingue vários tipos de imortalidade. Uma delas, diz ele, seria a imortalidade pessoal, dom reservado a alguns. Observa com Tácito, em sua Vida de Agripa, que "Não com o corpo morrem as grandes almas". Ao homenagear Marcuschi com a publicação destes artigos que ecoam ou respondem a interpelações de sua extensa e importante produção intelectual, poderíamos estar exercendo essa forma de imortalização.

Conhecendo Marcuschi, entretanto, como "marceneiro do mundo" (marceneiro deste "mobiliário", que ele tantas vezes tematizou), entendo que lhe interessaria mais a última das formas de imortalidade recenseadas por Borges. Consiste esta em uma espécie de imortalidade impessoal, uma imortalidade cósmica.

Diz Borges:

A linguagem é uma criação - vem a ser uma espécie de imortalidade. Estou neste momento usando a língua castelhana. Quantos castelhanos mortos estão vivendo em mim? Não importa minha opinião, nem meu julgamento; não importam os nomes do passado, se continuamente estamos

Este artigo está licenciado sob forma de uma licença Creative Commons Atribuição 4.0 Internacional,

que permite uso irrestrito, distribuição e reprodução em qualquer meio, desde que a publicação

original seja corretamente citada. https://creativecommons.org/licenses/by/4.0/deed.pt BR 
contribuindo para o futuro do mundo, para a imortalidade, a nossa imortalidade".

Quando pensamos nisso, entendemos melhor que a cultura humana tenha, nos últimos seis mil anos, desenvolvido tecnologias específicas para perenizar a fala e expandir a comunicação não presencial. Refiro-me, é claro, à escrita, da qual a comunicação eletrônica que hoje praticamos constitui magnífica exponenciação. Vivemos hoje num mundo inundado pela escrita e organizado por ela.

Platão, que abominava a escrita, seja pelo seu viés democratizante, seja por eliminar a vivacidade da réplica imediata, acaba por se lhe render. Segundo outra vez Borges (agora em Harvard, 1967/8), Platão recorre à escrita porque sente saudades de Sócrates. “Depois da morte de Sócrates, Platão terá dito a si mesmo: 'Ora, o que Sócrates diria sobre essa minha dúvida específica?' E, então, a fim de ouvir mais uma vez a voz do mestre a quem amava, Platão escreveu os Diálogos”.

Essa imortalidade, que corresponde ao legado comum humano o patrimônio imaterial de nossos feitos, nossos discursos, nossas crenças, nossas formas de sociabilidade, a aventura, que sempre tentamos, da intercompreensão - constituiu a matéria por excelência da inquirição marcuschiana.

O jovem a quem interessava a relação entre linguagem e classe social marca sua presença madura na cena da Linguística brasileira por introduzir entre nós a análise da conversação nos termos praticados pelos californianos Sacks e Schegloff, e, principalmente por desenhar, com Ingedore Koch, uma abordagem linguística do texto em que este aparece como a ponta do iceberg do contexto comunicativo que o 
sustenta e lhe constrói o sentido. Na expressão privilegiada de Fauconnier, "o signo não porta o sentido mas o guia".

Assim, Marcuschi, ao se debruçar sobre a cesura e a continuidade da fala com a escrita, foi levado a dois desenvolvimentos seminais: o primeiro, trabalhar com uma compreensão dinâmica de contexto comunicativo, como uma continuidade de semioses que se interdeterminam - da cena física (ou virtual) ao corpo dos participantes, às crenças implícitas, à ética do encontro focalizado. Nisso, Marcuschi e seus alunos e alunas se aproximam dos trabalhos de Gumperz, Duranti, Hanks, dedicados à sociologia interacional. Antes que um feixe de variáveis dispersas, o contexto se materializa com o próprio discurso, que, por sua vez, impacta e transforma a situação comunicativa na qual é enunciado.

O segundo desenvolvimento igualmente fecundo levou ao estudo da categoria de gênero textual, como ponto de encontro entre a diversidade dos usos situados da linguagem e as convenções discursivas idiomatizadas (e flexibilizadas) na própria instância comunicativa. É de se registrar a perspicácia da análise marcuschiana que, de certo modo, antecipa a pletora dos gêneros que haveriam de prosperar a partir da disponibilização de novas formas de conexão, oferecidas pelas TIC. Quem lê as sucessivas mensagens de atualização de recursos de aplicativos como o WhatsApp, ou o Telegram, sabe a que estou me referindo: comunicação individual ou em listas, cada qual com suas regras de cortesia específicas, assinalando com a inserção de emojis a nostalgia da comunicação via sinais corporais in praesentia...

A relevância teórica desta produção é multiplicada por mil pelo seu transbordamento para a área de educação no ensino de 
linguagem, mas, até mais importante, em outras disciplinas, com repercussão curricular e pedagógica na evolução qualitativa da educação brasileira. Contam-se às centenas as dissertações de Mestrado ou teses de Doutorado centradas na questão pedagógica, que tomam como régua e compasso a Linguística Textual koch-marcuschiana, especialmente através da categoria de gênero textual.

É claro que o interesse de Marcuschi pelo discurso e por sua interpretação o aproximariam da Linguística Cognitiva (LC). Em primeiro lugar, para tratar o processamento da referenciação, que envolve ativação da memória de curto prazo, muito mais que o mero estabelecimento de uma lincagem formal entre dois significantes, como o sugeriria a leitura rasa de Halliday e Hasan. Uma forma elegante e intuitiva de representar o labirinto das contrapartidas referencias é a Teoria dos Espaços Mentais, de Giles Fauconnier. Marcuschi flertou com essa teoria, mas o relacionamento não evoluiu por conta de uma agenda já tomada.

Em segundo lugar, o tratamento teoricamente robusto de fenômenos como a anáfora esquemática implica no reconhecimento da Semântica de Frames: o clássico exemplo "A polícia invadiu o bordel. Elas saíram pela porta dos fundos." requer que se reconheça que o pronome elas designa um Elemento Nuclear do Frame de bordel. Sem essa postulação específica, perdemos precisão e dissolvemos estruturas consolidadas da memória sociocultural em um fundo discursivo amorfo e inaccessível à análise. Em seus tratamentos do texto, Marcuschi alude a categoria de esquemas conceptuais sem mergulhar na discussão lexicográfica que os desdobramentos posteriores da Semântica de Frames ensejaram. 
É importante relevar as ressonâncias cognitivistas na linguística marcuschiana. Não o interesse em participar dos questionamentos teóricos tão presentes nas manifestações americanas da LC: no caso dos americanos, essa discussão, para além de seu peso epistemológico, corresponde a um acerto de contas edipiano com Chomsky. Marcuschi, de formação europeia, passa ao largo desta briga de família.

Não obstante, o diálogo com o cognitivismo na sua segunda geração, marcada pela virada pragmatista e pela cooperação interdisciplinar com a antropologia, com a psicologia, com a sociologia interacional, oferece um horizonte teórico mais rico do que aquele projetado pela Linguística Textual europeia. Assim, para Marcuschi, a coerência discursiva jamais é um atributo do texto, mas um elemento da interação comunicativa em que os sujeitos enunciam, negociam, se equivocam, hesitam, retificam, reiteram e se compreendem (ou não...).

Aliás, esta disposição de conviver com a diversidade teórica em favor de um apuramento empírico das análises reponta programaticamente na Introdução que Marcuschi escreve em 1997 para a coletânea editada por Koch e Monteiro de Barros, intitulada Tópicos em Linguística de Texto e Análise da Conversação. Diz Marcuschi:

\footnotetext{
Aspecto central na configuração dos temas e posições teóricas presentes nesta coletânea é a já apontada diversidade. Retorno a ela porque julgo-a decisiva para a própria sobrevivência e enriquecimento do grupo... Mas, também sem se perder num empiricismo crasso e positivista. Busca-se manter o espírito crítico com uma posição teórica bem fundamentada.
}

Por isso acredito que Marcuschi endossaria a presente coletânea que também reúne trabalhos bastante diversos. Há artigos que 
tematizam a linguagem no interior da tarefa educacional, focando, por exemplo, a experiência pedagógica de ensino/aprendizagem da escrita, apresentada por Filomena Varejão. Este trabalho constitui reflexão sobre a complexidade da relação escrita/oralidade, sobre a dinamicidade do contexto comunicativo, sobre os processos inferenciais de construção do sentido e, deste modo, homenageia o legado marcuschiano.

Outro artigo se debruça sobre um dos temas clássicos da investigação sociointeracional: a dêixis, no caso de Leonor Werneck dos Santos, assunto proeminente na produção de Marcuschi, como pesquisador e também como professor.

Por fim, há um grupo de textos que salientam as ressonâncias cognitivistas da linguística marcuschiana: o estudo da escolha de tempos verbais em manchetes de jornais online, para suscitar a categoria de imediaticidade epistêmica, apresentado por Lilian Ferrari e Caroline Soares; o estudo de formas correferenciais metafóricas, elaborado por Erik Miletta Martins; e uma discussão das dimensões sociocognitivas e interacionais da metáfora, em que Edwiges Morato e Nathália Luiz de Freitas interpelam a própria reflexão de Marcuschi sobre o tema.

No período mais maduro de sua reflexão Marcuschi apresentavase como um linguista sociocognitivo. De certo modo essa autodefinição articulava sua sensibilidade para a linguagem como prática social com a dimensão gerativa da linguagem como conhecimento, memória e processamento.

O tempo de Marcuschi, tão crispado - entre a política científica, o exercício abundante e generoso do magistério, a investigação 
acadêmica sempre sintonizada e desbravadora - não abriu janela para o diálogo com um dos mais fascinantes pensadores da atualidade, o psicólogo e primatologista Michael Tomasello.

A pesquisa de Tomasello, lastreada em robusto corpo de evidências (de campo e experimentais), verifica uma hipótese que Marcuschi subscreveria: a dimensão comunicativa/interacional das atividades humanas é absolutamente crítica para a emergência não só da gramática das línguas particulares, mas da própria capacidade da linguagem como disposição filogenética específica da espécie. Ao contrário do que pretende o último Chomsky, a comunicação não é um "efeito colateral" da linguagem, mas sua razão de ser. Em outras palavras, são comunicativas as bases da cognição humana.

Na verdade, o acúmulo das descobertas neste início de século XXI aponta para posição ainda mais radicalizada: o desenvolvimento filogenético da linguagem e da cultura humana decorreria de um conjunto de disposições para a cooperação e para o altruísmo, disposições inatas e específicas à espécie (TOMASELLO, 2008; 2014; 2016). Esta "hipótese radical" subsidia a proposta tomaselliana de uma "história natural" não só do pensamento como da moralidade humana.

Como se vê, defendo que livros que Marcuschi já não leu dialogam com seu legado de forma significativa, ilustrando essa imortalidade cósmica de que Borges nos falava em Belgrano.

De minha parte, sinto saudades de Marcuschi, do mesmo modo como Platão sentia saudades de Sócrates. Essas saudades, a leitura de seus textos mitigam. O que não é possível atenuar é a falta que sinto hoje de Marcuschi na cena pública brasileira. Nesta cena de universidades violadas e saqueadas; e da ciência reduzida a miséria sem 
dignidade. Sinto falta do lutador indômito em favor de uma academia democrática e altiva, elemento imprescindível à soberania de qualquer país. Para mim, o sentimento desta ausência é a homenagem definitiva. E a inspiração necessária para que continuemos na luta.

Maria Margarida Martins Salomão (UFJF)

Maria Margarida Martins Salomão é Professora Emérita da Universidade Federal de Juiz de Fora, Membro Permanente de seu Programa de Pós-Graduação em Linguística. Atualmente exerce a função de Deputada Federal pelo Partido dos Trabalhadores de Minas Gerais.

Em tempo, informamos que ainda dois artigos vieram a integrar esta edição especial em homenagem a Luiz Antônio Marcuschi: um artigo da professora pesquisadora da Universidade Nova de Lisboa, Portugal, Maria Antónia Diniz Caetano Coutinho, nos faz refletir acerca da natureza heurística da Linguística de Texto, área disciplinar a que se dedicou Marcuschi em tantos trabalhos, demonstrando o alcance alémmar das pesquisas da obra marcuschiana.

Por fim, fechamos a edição com a tradução de um texto inédito de Teun A. van Dijk, pesquisador que, dentro da Análise Crítica do Discurso, esculpe um nicho de trabalhos investigativos de viés Sociocognitivista, como podemos verificar em seu artigo que trata sobre movimentos sociais, frames e cognição, sempre passando pelo poder da linguagem como forma de construção de conhecimento, dialogando, dessa forma, com as pesquisas sociocognitivas marcuschianas. 


\section{Referências}

BORGES, J. L. Cinco visões pessoais. Brasília: Editora Universidade de Brasília, 1996, p.13-20.

. Esse ofício do verso. São Paulo: Companhia das Letras, 2000, p. 10-28.

FILLMORE, C. J. Frame Semantics. In Linguistics in the Morning Calm. Seoul, Hanshin Publishing Co, p.111-137, 1982.

FAUCONNIER, G. Mental Spaces: aspects of meaning construction in natural language. Cambridge: Cambridge University Press, 1994.

GUMPERZ, John. Discourse strategies. Cambridge: Cambridge University Press, 1982.

HALLIDAY, M.; HASAN, R. Cohesion in English. New York: Routledge, 1976.

HAUSER, M.; CHOMSKY, N.; FITCH, T. The faculty of language: what is it, who has it, and how did it evolve? Science, 298, 1569-1579, 2002.

MARCUSCHI, L. A. Apresentação. In KOCH, I. V.; BARROS, K. S. M. (Orgs.).

Tópicos em linguística de texto e análise da conversação. Natal: EDUFRN, 1997, p.7-8.

SACKS, H.; SCHEGLOFF. E.; JEFFERSON, G. A simplest systematics for the organization of turn-taking for conversation. Language, v. 5o, p. 696-735,. 1974.

TOMASELLO, M. The cultural origins of human cognition. Cambridge: Harvard University Press, 1999.

Origins of human communication. Cambridge: MIT Press, 2008. . A natural history of human thinking. Cambridge: Harvard University

Press, 2014.

. A natural history of human morality. Cambridge: Harvard University

Press, 2016.

Recebido em 22/12/o17. 
Revista Investigaç̧̃̃es, Recife, v. 30, n. 2, p. 1-9, jul./dez. 2017.

Aprovado em 22/12/o17. 